Fecha de recepción: mayo 2021 Fecha de aceptación: junio 2021 Versión final: julio 2021

\section{Diálogos tipográficos: lo conceptual y la figuración}

Gerardo Gómez Romero ${ }^{(1)}$

Resumen: El estudio del diseño en sus múltiples manifestaciones se plantea -en casos particulares- a través de antinomias; una confrontación de conceptos opuestos que exponen su significado en asociación de contrastante. A partir del binomio: lo conceptual y la figuración, se establecen reflexiones dialógicas con la configuración conceptual del signo lingüístico y la representación figurativa tipográfica, una antinomia propuesta como estrategia didáctica para la compresión de dos conceptos de uso frecuente en el diseño gráfico y que ahora se expone con los recursos propios de la tipografía. La configuración conceptual se ilustra con diez palabras con las que se dialoga a través de los signos tipográficos para mostrar su significado o alguna de sus acepciones, sin incorporar elementos figurativos que apoyen el significado. Por su parte, la representación tipográfica figurativa postula expresiones con los medios morfológicos de las fuentes tipográficas disponibles en los programas editores de diseño; un nivel de diálogo con el diseño donde el sujeto interpreta la figuración de forma más digerible. En esta última sección se ilustra el concepto de figuración con pasos proyectuales de un solo trabajo. Hasta el momento -al menos en México- no se conoce ningún estudio que aborde la construcción conceptual y la figuración tipográfica en correspondencia epistemológica con las relaciones dialógicas con el diseño, por lo que el presente artículo pretende ser un valioso documento referencial para la comunidad de diseñadores gráficos, comunicadores visuales y el público general.

Palabras clave: conceptual - figuración - significado - tipografía - diseño.

[Resúmenes en inglés y portugués en la página 39]

(1) Profesor de Carrera de tiempo completo, Titular "A" Definitivo, con adscripción al Posgrado de la Facultad de Artes y Diseño (FAD) de la Universidad Nacional Autónoma México (UNAM). Su cátedra y proyectos de investigación están vinculados con los temas de diseño, tipografía y publicaciones electrónicas. Obtuvo el grado de Doctor en Artes y Diseño por la misma Universidad. En el medio profesional se desempeña como diseñador gráfico eventual, logrando una carpeta de trabajos publicados en diversos soportes gráficos, durante los últimos 30 años. 


\section{Introducción}

El diseño y la tipografía lograron un desarrollo consistente durante todo el siglo XX; en el periodo de la modernidad -inicios del siglo pasado hasta la posguerra-; se establecieron sistemas racionales que se proyectaron al diseño gráfico y a la industria publicitaria. En este periodo, se consolidaron los fundamentos del diseño - las normas tipográficas- estructuras basadas en la retícula y avances en la tecnología electrónica, que dieron desarrollo a la práctica del diseño. Se ponderó el orden, tanto en los procesos de edición, como en la producción en serie; no obstante, para la segunda mitad del siglo pasado surgió la posmodernidad - un periodo de cambios y reflexión en el que se criticó severamente lo sucedido en la modernidad-: dos guerras mundiales, el Holocausto y la guerra de Vietnam, lo que provocó el rompimiento con los ideales de este tiempo y el rechazo de la 'razón' como su eje rector.

Las tendencias del diseño y aplicación de la tipografía posmoderna desafiaron la normatividad establecida en la academia, retomando sistemas experimentales y deconstructivos que revolucionaron las formas del trabajo tradicional del diseño. Ahora bien, el vocablo no solo se valoró en sentido lingüístico, también como signo visual. La interpretación de la palabra se desarrolló con base en un metalenguaje visual y plástico de elementos tipográficos. Acaso (2017, p. 25) señala que "el lenguaje visual es el código específico de la comunicación visual; es un sistema en el que podemos enunciar mensajes y recibir información a través del sentido de la vista." En la actualidad aun se debate sobre si el caracter tipográfico debe ser expresivo o limitarse a su comprensión literal. Por un lado, los conservadores del diseño postulan una tipografía legible, clara y objetiva, mientras que en el extremo opuesto los revolucionarios liberan las fronteras de toda norma y apuestan por la expresividad, los valores retóricos y la interpretación subjetiva.

El presente trabajo aborda un par de conceptos utilizados frecuentemente en diseño y la comunicación visual, en los que sus significados se contraponen. La antinomia: lo conceptual y la figuración está planteada como estrategia didáctica para la compresión de ambos conceptos a través de la expresión de los elementos tipográficos, en el marco de la comunicación visual. En la primera parte del artículo se desarrolla la configuración conceptual del vocablo y se ilustra con una decena de palabras que dialogan con su representación diseñística y configurativa para significar su concepto, o alguna de sus acepciones. En la segunda parte se presenta el opuesto; la representación figurativa tipográfica, con la que se establece el contraste con lo conceptual. Se desarrolla una puesta en escena, a través del diseño tipográfico, que favorece el diálogo con la plasticidad de los signos tipográficos en el terreno de la expresión visual, en el que se sustenta un nivel de interpretación mucho más digerible.

El punto de partida ha de ser observar la división, ya clásica, entre signos icónicos y signos plásticos. En los primeros, reconocemos tipos y referentes, que identificamos en la mente y a los que de alguna manera representan: provienen de una codificación de nuestra experiencia perceptiva sobre la que intervienen simultáneamente otros saberes y se asocian con facilidad a la noción tradicio- 
nal de lo figurativo. En los segundos, las formas, colores y texturas manifiestan sus posibilidades significantes como tales. [...] Así, el signo plástico se asocia en general a lo abstracto. (Ruder, 1983, p. 38)

Las reflexiones dialógicas que se establecen, tanto en lo conceptual como en la figuración se materializan a través del código tipográfico, en tanto se articula la comunicación entre el objeto y el sujeto que interpreta el mensaje visual. Se comprende como código tipográfico a todos aquellos elementos que integran una fuente o bien, familia tipográfica; letras, números y signos de puntuación en caja alta y baja, que son utilizados para la configuración de palabras y textos, con las variantes de forma, tamaño, estilo, valor, grano y orientación. Aunque el vocablo se establece en el campo de la lingüística, también confiere a la retórica la expresión de la palabra como imagen.

Los códigos definen y clasifican los conjuntos de elementos pertinentes -plurígrafos y constructígrafos- con base en los cuales se forma el sistema de comunicación gráfica, mediante la combinación según reglas básicas prefijadas. Los elementos pertinentes de los códigos se denominan signos - grafemas y grafectos-, el conjunto de los mismos se entiende como subcódigo -sensígrafos, quidvígrafos y multígrafos- y están basados en convenciones culturales cuyas propias condiciones posibilitan la articulación de mensajes. (Vilchis, 2004, p. 78)

Para la comprensión de la imagen se puede tomar el análisis en sentido de los modelos: semiótico y hermenéutico, ambos conducen a la significación del objeto. La disyuntiva de deslindar la formalidad que se emplea en este trabajo de configuración y diseño tipográfico queda establecida en cuanto se trata de una práctica suscrita en el terreno de la expresión visual, y aunque utiliza a la semiótica para esclarecer significados literales, el resultado final de cada proyecto de configuración y diseño no encaja con este modelo de análisis, más bien la interpretación se sustenta en una plataforma subjetiva de diálogos abiertos en dirección al terreno de la hermenéutica, ya que sería muy complicado un análisis de carácter científico.

[...] la semiótica supone que la significación se produce de manera precisa y resulta entonces accesible y mesurable. [...] La semiótica ofrecerá una visión que aborda el problema del sentido desde un andamiaje teóricamente estructurado para explicar la lógica de los signos, mientras que la hermenéutica buscará la apertura del sentido, su conexión con el mundo. [...] El sentido en hermenéutica es inseparable de la experiencia humana y su coextensividad en el lenguaje. (Lizarazo, 2009, p. 22).

La reflexión dialógica en el diseño y la configuración tipográfica tiene correspondencia directa con las interpretación del sujeto y su contexto. Esta es la vía sobre la que se traza el camino hacia la representación conceptual y figurativa de los signos tipográficos. Configuración y diseño son dos palabras independientes que se emplean para definir el tipo de 
trabajo realizado; la configuración tipográfica se construye como una estructura de texto por medio de fuentes tipográficas establecidas disponibles en los programas computacionales editores de diseño,-también en venta en línea-. Por su parte, el diseño tipográfico implica en su concepción procesos sistemáticos personalizados con base en fundamentos del diseño, normas tipográficas y reglas de composición en los que se presume de una idea original y creativa, en correspondencia con los valores estéticos, pragmáticos, semióticos y sintácticos del signo. La reflexión dialógica en el diseño y la configuración tipográfica se consolida cuando el individuo responde con una interpretación que da sentido a lo leído y observado, ponderando la interpretación como lo más importante del proceso de comunicación en razón de comprender mejor el mundo y los signos que lo rodean. Vilchis (2006, p. 1) afirma "Una de las determinantes de la evolución de los seres humanos es el entendimiento del mundo, del contexto y de los fenómenos que le rodean."

\section{El desvío de la norma en la retórica tipográfica}

La retórica es una disciplina que encuentra respuestas conscientes e inconscientes a partir de recursos de la imagen y la palabra. Carrere (2009, p. 18) considera que la retórica está construida por experiencias sensoriales y conceptuales favorecidas por la contemplación de una obra de arte. El signo lingüístico se configura a partir de asociación de letras con la misión de ser leído, más aun tiene la capacidad de cautivar por su apariencia al público, por lo que actualmente se ha puesto mayor atención en su presentación formal. Al reflexionar sobre la forma de las letras y las miles de fuentes tipográficas existentes en el mercado digital, se puede dimensionar el potencial de significación a partir de la retórica tipográfica. En retórica, la palabra es valorada como imagen y la imagen como palabra, donde los sentidos se relajan para dar lugar a la distensión en el plano del lenguaje visual. En retórica, el signo lingüístico se presenta de forma distinta a lo habitual. Lo habitual en la representación de un texto consiste en respetar las normas que rigen la gramática, en tanto que las palabras correspondan con el significado literal. Entonces, cuando se habla de hacer las cosas de forma distinta a lo habitual, se establece el 'desvío de la norma', que para la configuración tipográfica resulta de posibilidades ilimitadas. El desvío de la norma está ligada con la trasformación del lenguaje y los códigos que el individuo utiliza y reconoce en su ambiente natural. La retórica referencial en la práctica compositiva del diseño establece una forma específica de hacer las cosas, se proyecta de manera local con un estilo que se imprime en la configuración tipográfica.

Habrá que tomar en cuenta que el discurso en retórica tipográfica puede determinar vínculos con diversas imágenes como la fotografía, la pintura, la escultura, el dibujo, el diseño, la arquitectura, el urbanismo, etcétera. Los tratados de la retórica establecen el uso del lenguaje expresivo y sus posibles modificaciones sistematizadas en tropos y figuras retóricas como metáfora, metonimia, repetición, acumulación, símil, antítesis, paradoja, ironía, hipérbole; que se incluyen dentro de un grupo más extenso. Los tropos se refieren a la sustitución de una expresión por otra, en sentido diferente a lo habitual. Se establecen 
en dos grandes grupos: metafóricos y metonímicos; la distinción entre ambos radica en que los primeros tiene elementos presentes y los segundos elementos ausentes. Por su parte, la metáfora consiste en sustituir un término real por otro imaginario, mientras que la metonimia sustituye un término por otro, un fenómeno de cambio semántico. Es frecuente que metáforas y metonimias aparezcan relacionadas entre sí, y también con otras figuras retóricas, ya sean de expresión o de contenido.

\section{Hacia una construcción conceptual}

El ser humano inmerso en diversidad de signos que constantemente lee e interpreta por antonomasia, construye elementos conceptuales como una necesidad de comprender el mundo que lo rodea. La lectura visual y los significados que el individuo interpreta dependen de varios factores: capacidades cognoscitivas, conocimiento del contexto cultural en el que se encuentra inmerso y experiencias de vida que día tras día va adquiriendo. En la segunda mitad del siglo pasado, la lectura visual del signo lingüístico y su interpretación se convirtió en un tema controversial, debido a que la tipografía tomó nuevos rumbos de expresión y significación. El vocablo adquirió fuerza por su forma y estableció un lenguaje visual que fue más allá del significado literal. La sociedad posmoderna rechazó tanto las formas tradicionales de las fuentes tipográficas como las conservadoras composiciones de textos de aquella época; en esta tesitura la unidad lingüística encontró nuevos caminos de expresión que se proyectaron en el campo de la comunicación visual.

La palabra conceptual procede del latín conceptus y está referida al concepto, idea que se crea o forma el entendimiento; su campo de acción está en concebir un pensamiento (Diccionario RAE, 1970, p. 335). Para Rodríguez (2005, p. 217) lo conceptual son elementos invisibles como componentes estructurales de una forma. Según el Diccionario Akal de filosofía (2004, p.186), lo conceptual se remite a la teoría del significado de la función. A partir del siglo XX, alfabetos Sans Serif (sin patines) como 'Futura' -diseñada por Paul Renner en 1927-, contrastaron con las formas tipográficas de siglos anteriores. A través de su creación tipográfica, Renner pretendió representar el progreso de la humanidad en un mundo -entonces llamado moderno-, y aunque no fue parte activa de la Bauhaus, congenió con la ideología de la escuela alemana, donde se instauraron nuevas tendencias del diseño a partir de las formas geométricas básicas, en las que se inspiró para la creación de la fuente Futura. La preocupación del mencionado tipógrafo en ese momento se centró en la aceptación del diseño geométrico de tipos Sans Serif con los que el público no estaba familiarizado (Martínez, 1990, p. 97). La tipografía sin patines también llamada de 'palo seco' expresó claridad y sencillez en sus formas, eliminando cualquier connotación de significado definido. En las décadas subsecuentes la aceptación de esta nueva tendencia de diseño de fuentes se pronunció con cientos alfabetos, destacando la Helvética -rediseñada en 1957 por Max Miedinger- por ser la fuente tipográfica más utilizada en todo el mundo desde su creación hasta la época actual. 
Bajo el carácter visual, la significación de textos puede variar, depende de factores contextuales de grupos, pueblos y ciudades, de tal suerte que la forma de los caracteres tipográficos puede direccionar una idea en concordancia con la construcción mental del individuo. Por ejemplo, una letra 'i' en caja baja se puede asociar con la representación abstracta de la figura humana, esta interpretación de tipografía-figuración se debe a una construcción retórica que el ser humano crea en su mente. El logotipo Families (Familias) diseñado por Herb Lubalin (1918 - 1981) es un claro ejemplo de la representación conceptual de la palabra. La interpretación del vocablo estriba en la figura de la madre, padre e hijo con las letras 'ili' que corresponde con la concepción cultural de familia. Un discurso visual que se logra a partir de la asociación sintáctica de los caracteres.

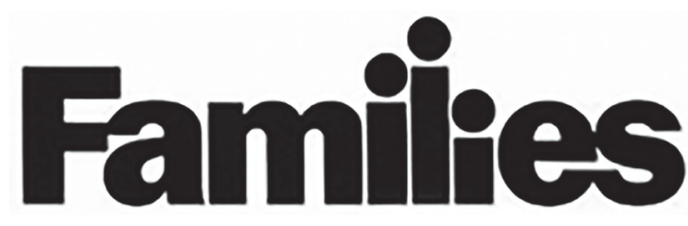

Figura 1. Logotipo diseñado por Herb Lubalin. Fuente: https://a-g-i.org/design/families

En las décadas de 1950 y 1960 en los Estados Unidos, la práctica del diseño gráfico enfatizó la forma de las letras debido a que el signo lingüístico también fue valorado como imagen en el sentido conceptual y figurativo. Martínez (1990, p. 141) apunta que "Las letras llegaron a ser objetos y los objetos se volvieron letras. Sobre todo, las letras se transformaron en imágenes y las propiedades visuales de las palabras se fueron explorando para expresar conceptos." En aquellas décadas de revolución ideológica por el cambio generacional, el diseñador Herb Lubalin -que algunos lo consideran como el padre de la tipografía conceptual- designó a este estilo como expresionismo gráfico; un medio formal para la representación del concepto ligado a la expresión visual, utilizando las formas de la tipografía. A la representación del vocablo le dió el nombre de 'Tipograma' un poema visual tipográfico reticente. Otros aportes de Lubalin que trascendieron y trazaron nuevos caminos en el diseño gráfico fueron:

Sintetizó las dos corrientes del diseño gráfico americano, por un lado los conceptos visuales/verbales y, por otro, la tipografía figurativa. Abandonó las normas tradicionales de la tipografía y vio al alfabeto como forma y como mensaje. [...] Comenzó a cortar sus galeras y a reorganizarlas. [...] Cerró los espacios, amplio las letras, las traslapó, hizo toda una serie de nuevas posibilidades y, sobre todo, derribó la barrera entre la palabra y la imagen. (Martínez, 1990, p. 141). 
La configuración conceptual de un vocablo se realiza con base en dos etapas: construcción conceptual y construcción formal. En la primera, la investigación sobre el significado del vocablo finca las bases del proyecto y establece el proceso de conceptualización al que tendrá que ser remitido; el desempeño pragmático del signo con relación a las convenciones culturales y la relación sintáctica con otros signos, clarifican la representación del concepto. La segunda etapa está ligada con el diseño y la configuración de la palabra, se trata de la composición y acabado a través de los procesos análogos y analógicos insertos en la técnica del diseño gráfico. Otro elementos que se consideran en el proceso de creación es el estilo que distingue al diseñador y al nivel de expresión que se imprime en las estrategias conceptuales y de diseño. La representación conceptual del signo lingüístico es una tarea compleja, de capacidades cognitivas, creativas y técnicas, en el tenor de lograr originalidad y aplicación en los procesos sistemáticos de la configuración conceptual. Los esfuerzos se centran en lograr la significación de la unidad lingüística sobre una plataforma de distensión, ambiente lúdico de interpretación metafórica. “[...] la metáfora como fenómeno trasciende lo lingüístico y su significado puede ser caracterizado desde términos semánticos o bien, basarse en las intenciones comunicativas, en cuyo caso los procedimientos son de expresión y comprensión" (Dascal, 1999, p. 99).

Existe similitud entre la configuración conceptual del vocablo y la imagen logotípica. La palabra 'logotipo' proviene del griego lógos, que significa razón; y tipo del latín týpos con acepción referida a la letra de imprenta. (Diccionario de la lengua Española). Un logotipo es un tratado de letras, -no incluye una imagen simbólica- solo se involucran caracteres tipográficos que configuran la palabra. En este escrito, no se persigue el desarrollo del concepto logotipo, éste requiere de una metodología específica que corresponde a la identidad gráfica institucional, personal o corporativa que ahora no se compete, sin embargo, la configuración conceptual del vocablo que ahora se ocupa, comparte intersecciones con la imagen logotípica. Lizarazo (2009, p.56) apunta "La imagen nos pone en otra situación: la decodificación de las denotaciones exige un detenimiento en las propiedades plásticas (y en ciertas ocasiones, solo dichas propiedades vienen al caso, como ante la imagen abstracta)".

La configuración conceptual del signo lingüístico y la reflexión dialógica con el sujeto tiene correspondencia con los procesos de la comunicación visual. Es una práctica que el ser humano desarrolla por antonomasia desde los primeros años de su vida; por ejemplo, un niño o niña percibe de forma inmediata el mundo que le rodea, lo interpreta a través de un papel sin necesidad de haber tomado clases de dibujo, tampoco es necesario que alguien le explique los significados. En este sentido funciona la configuración conceptual de la palabra, se requiere claridad, legibilidad e inmediatez de interpretación. "[...] esto caracteriza la inmediatez, la razón por la que el lenguaje visual es un tipo de comunicación que a un determinado nivel no necesita aprenderse para entender su significado" (Acaso, 2017 , p.27). Si la interpretación de la palabra no se logra de forma inmediata o se hace difícil la comprensión del concepto, entonces no se logra el objetivo de la representación conceptual, por tanto se invalida la propuesta. 


\section{Configuración conceptual del signo lingüístico}

A continuación se presenta una decena de vocablos -elegidos de forma aleatoria por quien suscribe este artículo- con el propósito de ilustrar la construcción conceptual de los mismos a través de la configuración tipográfica. El diálogo entre la unidad sígnica y el sujeto lector se establece con el fin de hacer una posible interpretación conceptual a partir del tratado tipográfico. No se pretende el desarrollo metodológico de esta propuesta tipográfi$\mathrm{ca}$, sin embargo, en los ejercicios propuestos se incorporan algunos pasos y estrategias del proceso proyectual. La fase inicial se focaliza en la investigación del significado del vocablo que se presenta. La investigación se apoya en la documentación extraída por cualquiera de las fuentes de información: bibliotecas, hemerotecas, diccionarios, enciclopedias, sitios web, entre otros. Así que la información obtenida en esta etapa es significativa para lograr el objetivo que se convoca. "La investigación científica se ubica entonces como elemento inseparable y unificador de toda tesis metodológica, dado que se practica en todos los campos del conocimiento con vínculo directo a la metodología general." (Vilchis, 2014, p.31). La finalidad de la investigación consiste en adentrarse en el concepto de la palabra en función del texto y el contexto. En ocasiones no es suficiente recurrir al significado literal, se requerirá observar el entorno social en escenarios de locación real, esta acción es, tal vez, el trabajo de investigación más fiel.

La primera palabra que ilustra la configuración conceptual es 'guerra' (figura 2). Evidentemente no es necesario inmiscuirse en una guerra para la comprensión del concepto, no obstante, un par de acepciones del Diccionario de la Real Academia Española direcciona el significado el cual refiere: rompimiento de paz entre dos o más potencias; oposición de una cosa contra otra. Con esta plataforma, la configuración conceptual que a continuación se presenta rompe con la estructura gramatical en su línea de base, así como con el cambio de fuente, dirección y escala de la letra 'rr' que sugiere la confrontación de dos ideas que se contraponen en "rompimiento de paz". Representación conceptual que deja al margen elementos figurativos como armas, sangre o violencia humana. La significación se logra a partir del diálogo con los caracteres tipográficos y la construcción conceptual de la palabra.

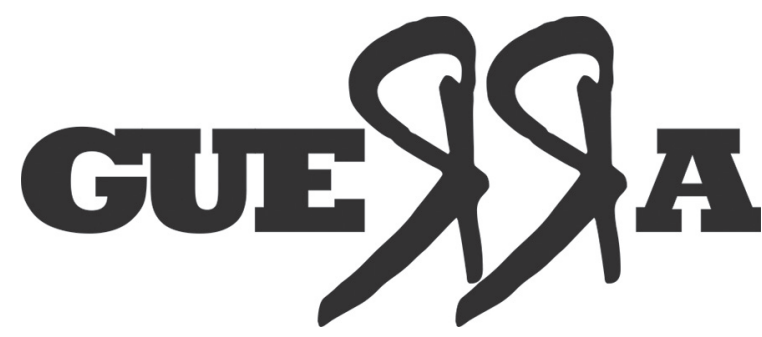

Figura 2. Configuración conceptual de guerra.

Creación: Gerardo Gómez Romero. 
Existe la relación referencial en la conceptualización del vocablo con el contexto cultural, esta condición es determinante para la interpretación. Para comprender la configuración de la palabra 'terrorismo' (figura 4) es fundamental conocer los acontecimientos sucedidos el 11 de septiembre de 2001 con el atentado a las Torres Gemelas en Nueva York (figura 3). El contexto cultural es la percepción que el ser humano tiene frente al mundo. Vilchis (2002, p. 42) refiere al contexto como "toda realidad que rodea un signo, es un acto de percepción visual o un discurso". El contexto cultural se relaciona con toda actividad de la vida cotidiana en sus diversos vínculos: social, político, religioso, etcétera. En las siguientes figuras 3 y 4 se observa el vínculo entre el signo fotográfico y el signo lingüístico. La reflexión dialógica entre ambos se establece a partir del tratado de los caracteres tipográficos; la forma y tamaño de la 'RR' propone la interpretación conceptual del evento terrorista.

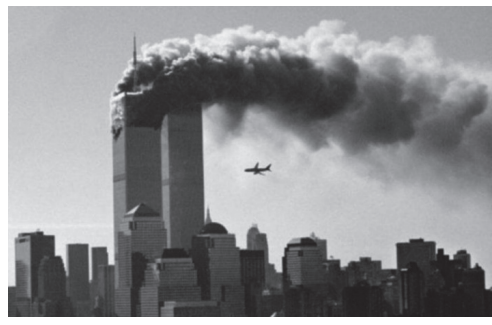

Figura 3. Atentado a Torres Gemelas de NY. Fuente: https://heraldodemexico.com.mx

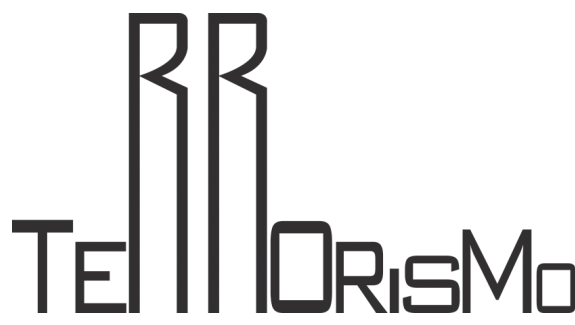

Figura 4. Configuración conceptual de terrorismo. Creación: Gerardo Gómez Romero

El ser humano percibe e interpreta todo tipo de signos, al mismo tiempo, adquiere las experiencias con las que construye conocimiento. Con base en esas estructuras del conocimiento genera el pensamiento; surgen las ideas, se formulan los conceptos. A partir del objeto se puede concebir un concepto o bien, del concepto es factible construir el objeto, en tales casos se expresa el concepto para la interpretación de un tema, cosa, diseño, etcétera.

La configuración conceptual de 'casa' (figura 5) plantea la protección que un individuo hace para salvaguardar su integridad. La morfología del caracter 'A' corresponde al estilo Sans Serif (sin patines) con la intención de eliminar cualquier tipo de ornamento que desvíe el propósito de la significación. La sociedad de unidades tipográficas se puede interpretar como el resguardo de un grupo de personas bajo un techo que brinda cobijo. El diálogo con el diseño a través de la imagen tipográfica no plantea el modelo convencional de casa, empero, corresponde a una construcción conceptual de significado. 


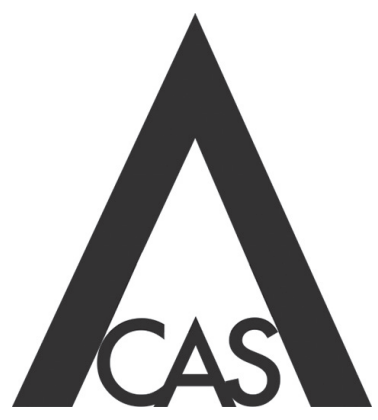

Figura 5. Configuración conceptual de casa.

Creación: Gerardo Gómez Romero

La relación sintáctica de caracteres tipográficos de la palabra es uno de los factores que el diseñador contempla en la búsqueda de la representación conceptual. El diálogo que sujeto y objeto entablan es posible a través del fenómeno de semiosis; un proceso neuronal del pensamiento y la reflexión que al final propone una idea de significado.

La semiosis tiene sentido para la comunicación gráfica no lineal, ya sea en el acercamiento semántico a la comprensión de los fenómenos, o los objetos de diseño o en la aproximación proyectual para profundizar en las condiciones y parámetros de interpretación, tanto de forma como de fondo de los problemas de diseño (Vilchis, 2004, p. 127).

La sustitución de un elemento real por otro imaginario es lo que define la 'metáfora', -quizá ésta sea la figura retórica más reconocida de alrededor de cien tropos-. La metáfora tiene conexión con la analogía, en donde se establece un tipo de comparación entre dos elementos de diferente orden. Un ejemplo, si se dice que "el cielo está llorando", bien se podría aludir a que está lloviendo, analogía expresada en lenguaje figurado o metafórico. La siguiente configuración de 'secuestro' (figura 6) se remite a la privación ilegal de la libertad de un individuo, evento que tiene como fin el intercambio del sujeto por dinero.

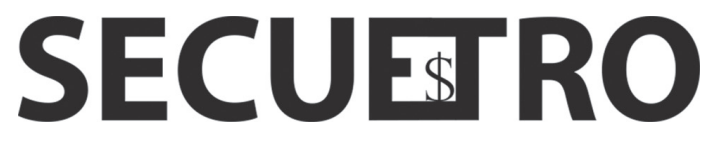

Figura 6. Configuración conceptual de secuestro.

Creación: Gerardo Gómez Romero 
La configuración conceptual de un vocablo con carácter de expresión, proyecta una idea diferente en su gramática. Sustituye la construcción convencional por otra forma que rompe con las normas de la lingüística. La divergencia del pensamiento permite la apertura de la expresión y la libre interpretación. Al respecto, Fontana (2012, p.73) apunta que:

La labor del tipógrafo (diseñador) encierra una serie de habilidades de interpretación y traducción cultural. Pero este no es el objetivo puramente específicamente disciplinario; para cumplir este compromiso la tipografía necesita interrelacionarse, ponerse al servicio de la antropología y la lingüística.

Esta posibilidad alterna podrá ser efectiva siempre y cuando la significación del vocablo corresponda con alguna de sus acepciones. En la siguiente palabra 'embarazo' (figura 7) la representación del contraste positivo-negativo y la sociedad yuxtapuesta de las letras B y a, establecen conexiones semánticas que corresponden con el concepto de embarazo. Ahora bien, la intervención en la letra ' $\mathrm{B}$ ' -con una doble intención- se valida en cuanto cumple con la representación del caracter tipográfico. La silueta de una mujer embarazada es una construcción mental de asociación subjetiva.

\section{emErazo}

Figura 7. Configuración conceptual de embarazo.

Creación: Gerardo Gómez Romero

El tratado de 'sinécdoque' consta la sustitución de significado de una cosa por el concepto de otra en relación de inclusión, en donde una parte representa al todo y el todo es representado por la parte. En el siguiente configuración de 'elevador' (figura 8) la inclusión procede con un par de triángulos equiláteros: punta arriba y punta abajo, que representan respectivamente las letras $\mathrm{A} \mathrm{y} \mathrm{V}$, esta unidad de asociación sígnica representa el concepto de elevador como el todo, donde se suele observar únicamente los triángulos en la parte superior de los elevadores tradicionales, y no todo el aparato estructural. El vocablo muestra en su composición equilibrio compositivo a partir de su centro de gravedad con la fortuna de contar con tres caracteres tipográficos por lado, lo que connota cierta estabilidad, seguridad, etcétera, favoreciendo la estética de la configuración. 


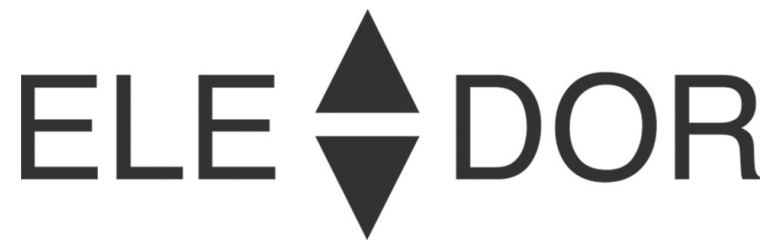

Figura 8. Configuración conceptual de elevador.

Creación: Gerardo Gómez Romero

La aplicación de la figura retórica de 'elipsis' en tipografía reside en la omisión de un caracter del vocablo, una parte de la letra o bien, un fragmento de un texto. Aplica en la ausencia de algún signo de puntuación, e inclusive la ausencia de los espacios en blanco. Es el caso de la configuración de la palabra 'espíritu' (figura 9) se elimina solo una parte de la letra 'í, en alusión de algo que existe pero que está más allá de la forma material, la sola presencia de la acentuación abre la reflexión dialógica con los caracteres tipográficos para su posible interpretación del concepto espíritu. A pesar del inexistente elemento tipográfico, la lectura de la palabra no se dificulta y se comprende el concepto con inmediatez. El tropo 'elipsis' forma parte de las tendencias del diseño actual, por lo que es recurrente ver su aplicación en la publicidad.

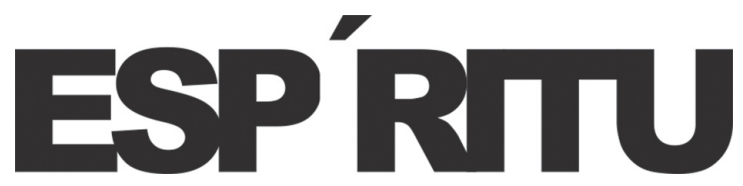

Figura 9. Configuración conceptual de espíritu.

Creación: Gerardo Gómez Romero

En retórica tipográfica, la personificación consiste en la sustitución de un carácter tipográfico por la representación abstracta de la figura humana. En el siguiente configuración de 'infidelidad' (figura 10) se concibe la sustitución del caracter 'i' con la representación humana. La configuración de la palabra vinculada con el estilo de fuente estratégicamente seleccionado, resuelve la sustitución abstracta. A través de los valores plásticos de la tipografía, es posible la construcción retórica y la conceptualización del vocablo, en correspondencia con una de las acepciones que refiere a un tercero inmiscuido entre una relación de pareja. 


\section{iNF! DELIDAD}

Figura 10 . Configuración conceptual de infidelidad.

Creación: Gerardo Gómez Romero

En la configuración conceptual del vocablo no sólo es importante lograr la acción del diálogo y la reflexión para la posible significación, también lo es la forma estética. La persuasión compositiva es un factor preponderante para lograr incidir en el lector, si el diseño no es cautivador se perderá el interés y por consecuencia la configuración tipográfica pasará inadvertida, -no habrá los nexos para la comunicación-. En el marco del diseño gráfico y la comunicación visual, la forma con la que se presenta un objeto de diseño no puede eludir esta responsabilidad. En la configuración de la palabra 'acercamiento' (figura 11) el aumento de la visión en los últimos caracteres pareciera referenciar a una lupa, pero no es así, únicamente se emplea la figura retórica de 'hipérbole' que consiste en la alteración exagerada de la realidad en el plano del contenido. "La percepción es un proceso constructivo y continuo que se construye por la relación entre una institución convencional y un modelo plástico" (Lizarazo, 2009, p. 57).

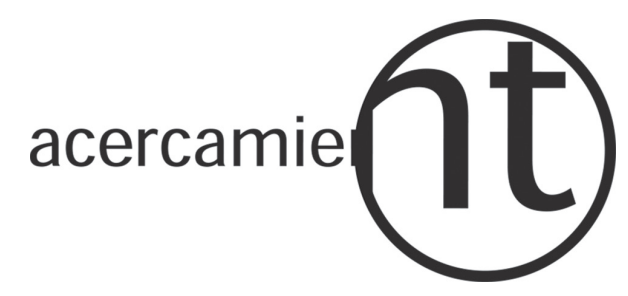

Figura 11. Configuración conceptual de acercamiento.

Creación: Gerardo Gómez Romero

En esta propuesta de configuración conceptual del vocablo se restringen los elementos figurativos, únicamente se incluyen signos del código tipográfico. Observar las características morfológicas de la tipografía es una acción de diálogo con los detalles mínimos de las letras. A través de la reflexión, el sujeto transforma las ideas en conceptos en un ambiente de distención y espacio lúdico propio de la comunicación visual. La gramática normativa constituye las formas de hablar y escribir correctamente, sus reglas de uso son claras y no 
especulan en su aplicación, pero en el terreno de la expresión visual la gramática se valida a partir el pensamiento alterno; la divergencia de ideas creativas posibilita soluciones que quebrantan la estructura gramatical. En la siguiente configuración de 'bullying' (figura 12) la sintaxis de los caracteres tipográficos entablan conexiones dialógicas de asociación cultural y conocimiento semántico del vocablo. La configuración tipográfica del signo lingüístico incorpora únicamente caracteres tipográficos que varían en su posición, la intervención en los caracteres protagonistas no los hace figurativos, se interpretan como imagen tipográfica dando sentido a una acción de significado conceptual.

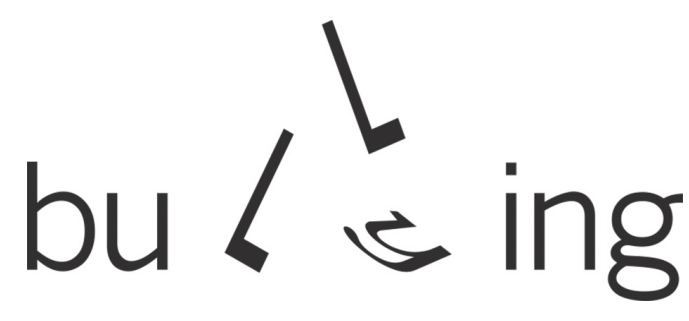

Figura 12. Configuración conceptual de bullying.

Creación: Gerardo Gómez Romero

\section{Representación figurativa tipográfica}

La figuración establece la contraparte con lo conceptual. La antinomia plantea la comprensión de ambos conceptos a partir del contraste en niveles de representación que favorece el diálogo con la plasticidad de los signos tipográficos. La figuración está referida a la acción de proyectar algo por cualquier medio, también se concibe como representación visual con tendencia artística, motivo que ahora nos ocupa. La representación figurativa utiliza los medios computacionales editores de diseño, con la disponibilidad de fuentes tipográficas, este tipo de trabajo encaja en el área de la ilustración con tendencia a romper las técnicas de representación tradicionales.

Cuando la tipografía se representa como forma la interpenetración es de clase icónicotipográfica. Así, el signo lingüístico está en posibilidad de construir una imagen figurativa. La imagen icónica se proyecta a través de un complejo código neuronal, en donde la mente genera la imaginación. El efecto imaginativo también se puede procesar a través de las palabras tanto escritas como verbales. "La función figurativa es una categoría perceptual y cognitiva tan completa como otras y tan capaz como ellas de crear sentido, a partir de su lógica estructural, sin necesidad de trasposición ni de relacionarlas con los sistemas verbales" (Soriano, 2004, p. 39).

El pensamiento figurativo aleja la especulación y otorga imágenes reales y abstractas que permiten la interpretación del mundo. Por medio de la expresión tipográfica se crean estereotipos de representación gráfica cuyo vínculo con la realidad material construye el valor 
morfológico que enfatiza o disminuye el carácter estético del objeto. Se tienen registros de la realidad figurativa desde la prehistoria, es el caso del primer Homo Sapiens que ha dejado imágenes figurativas sacadas de su contexto ecológico, como se aprecia en la bóveda de Altamira, España, que narran una actividad cotidiana de caza de animales. Es probable que la primera expresión figurativa con tipografía tenga sus orígenes en la poesía visual, con el poema de Simias de Rodas El Huevo (hacia el año 300 a.C.), en donde la lectura va del centro hacia la periferia, es uno de los poemas figurados más antiguos. En tiempos más recientes, la figuración tipográfica se manifestó en la primera mitad del siglo XX, con los caligramas de Guillaume Apollinaire, su propuesta de composición figurativa tipográfica rompió con la estructura sintáctica y pragmática del poema tradicional. La proyección plástica del artista innovó las estructuras literarias llevándolas al terreno de la expresión visual.

Para abordar el tema de figuración tipográfica se expone un solo motivo: 'La victoria de Samotracia', escultura descubierta en la isla de Samotracia en 1863 en Grecia, y que data del siglo II a.C., correspondiente al período helénico, la pieza está tallada en mármol, mide 2.5 metros de altura y pesa 1.5 toneladas. Representa a Niké, la Diosa de la victoria de la mitología griega, la cual se la asocia con la victoria naval de Rodas. Actualmente se encuentra expuesta en el Museo de Louvre en París-Francia (figura 13). El proceso para la representación figurativa de la escultura griega parte de una fotografía original que se toma como prototipo, la cual es importante obtener de forma nítida, y cuyos elementos de composición expongan los rasgos más característicos de la pieza artística ya que éstos serán fundamentales para el trabajo de reinterpretación tipográfica. La relación de diálogo con las fuentes tipográficas por su forma está dispuesta en una cantidad enorme de fuentes tipográficas disponibles en el mercado digital; la cualidad de presentación en caja alta y baja, los estilos ligero, pesado extendido, condenado, cursivo, así como el puntaje, dirección, espaciado, color y tonalidades son determinantes para la representación figurativa.

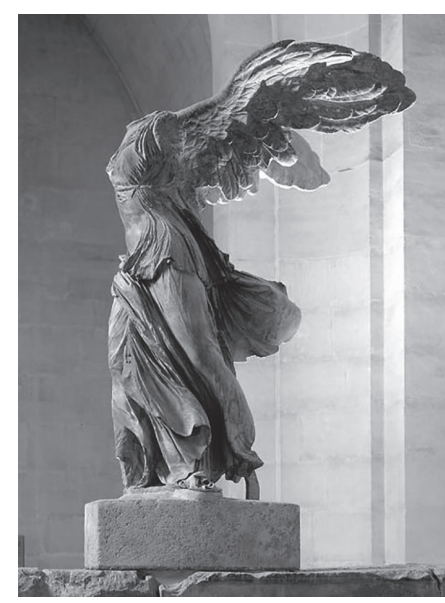

Figura 13. La victoria de Samotracia.

Fuente: Museo de Louvre en París-Francia. 
En la siguiente tabla (figura 14) se muestra una selección de fuentes para la reinterpretación tipográfica con la palabra 'samotracia' escrita en caja alta y baja, ya que el discurso morfológico de cada letras se presenta con diferente expresión. La estrategia gráfica que el diseñador utiliza es por sustitución de la forma, un trabajo que exige de la observación y los medios estratégicos que posibiliten la analogía entre la imagen fotográfica y la plasticidad de las formas tipográficas.

\begin{tabular}{|l|l|l|}
\hline \multicolumn{1}{|c|}{ NOMBRE DE LA FUENTE } & \multicolumn{1}{|c|}{ CAJA ALTA } & CAJA BAJA \\
\hline Zapfino - Regular & SAMOTRACIA & samotracia \\
SingPainter - HousesScrp & SAMOTRACIA & samotracia \\
Luminari - Regular & SAMOGRACIA & samotracia \\
Hobo - Std Medium & SAMOTRACIA & samotracia \\
PT Sans Caption - Bold & SAMOTRACIA & samotracia \\
Noteworthy - Light & SAMOTRACIA & samotracia \\
Gill Sans - Light Italic & SAMOTRACIA & samotracia \\
Savoye LEt Plain:1.0 & SAMOTRACI & Asamotracia \\
Snell Roudhand - Black & SMWOFRCOTC & samotracia \\
Baskerville - Italic & SAMOTRACIA & samotracia \\
Avenir Next - Ultra Light & SAMOTRACIA & samotracia \\
Brush Script MT - Italic & SAMOTRACIAt & samatracia \\
\hline
\end{tabular}

Figura 14. Tabla de selección de fuente tipográficas.

Para la representación figurativa de La victoria de Samotracia se adecuan los caracteres tipográficos - pieza por pieza- con las formas del prototipo. En este punto el diseñador interpreta la forma del signo fotográfico con la expresión de la tipografía, en diálogo con cada una de las partes, es un proceso de observación y sustitución asertiva. Formular analogías entre un elemento real y los signos tipográficos tiene como propósito la representación figurativa de la imagen. Ahora se puede disponer de todos los caracteres dispuestos en la tabla anterior que inspire al trabajo de reinterpretación. En las siguientes figuras 15, 16 y 17 se muestra el proceso de construcción figurativa. 


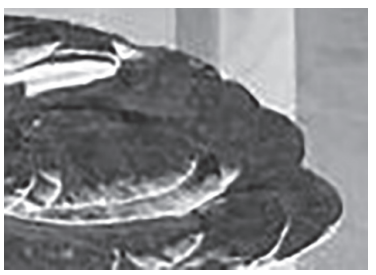

Figura 15. Detalle del prototipo.

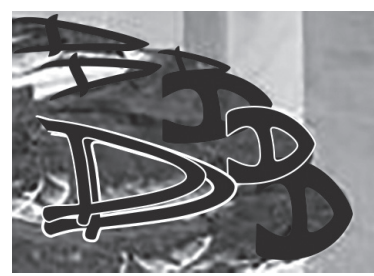

Figura 16. Reinterpretación.

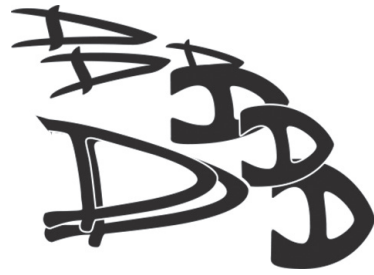

Figura 17. Representación final.

El trabajo diseñístico de transformar una imagen real por la figuración tipográfica permite al diseñador plasmar la visión personal que tiene sobre la realidad, así como la oportunidad de expresar su estilo que lo diferencia de los demás diseñadores. La representación figurativa tipográfica se suscribe al terreno de la expresión visual, donde los recursos de fuentes tipográficas son accesibles en los programas editores de diseño y disponibles por miles en venta en línea. Las posibilidades creativas con esta técnica de representación son ilimitadas y el estilo suele ser bien aceptado por el público general, habiendo aplicaciones en todo tipo de soportes gráficos. A continuación se presenta la versión final de la representación figurativa tipográfica (figura 18).

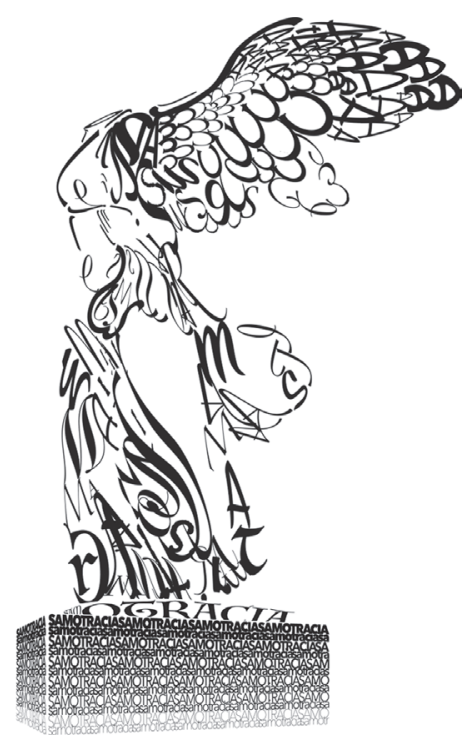

Figura 18. La Victoria de Samotracia. Representación figurativa tipográfica. Creación: Gerardo Gómez Romero 


\section{Conclusiones}

A partir del binomio entre lo conceptual y la figuración es posible construir y comprender dos conceptos que frecuentemente se unen y al mismo tiempo se confrontan por sus significados equidistantes. Estos conceptos, puestos en el escenario del diseño gráfico se presentan bajo sistemas de representación alterna y con los medios propios de la tipografía; tanto en la configuración conceptual del vocablo como en la representación figurativa tipográfica, se establecen estrategias sistémicas con fines de significación en el marco de la expresión visual. A través del metalenguaje plástico de letras y palabras se transforma la realidad por una expresión del pensamiento inserto en la retórica y la metáfora tipográfi$\mathrm{ca}$, con el propósito de presentar una propuesta diferente que persuada al lector, tomando en consideración las implicaciones culturales del medio contextual. Es frecuente que los diseñadores gráficos -al inicio de un proyecto- se encuentren en la disyuntiva de seguir el camino de la representación conceptual u optar por el desempeño figurativo. No es mejor uno que otro, la elección de la estrategia dependerá de lo que mejor convengan a la marca, producto o de quien ofrece un determinado servicio. En la actualidad, el signo lingüístico y los textos en general no solo son valorados por su contenido, cada vez más son apreciados por su forma. El carácter morfológico de la tipografía en las diferentes aplicaciones -principalmente en el diseño y la publicidad- favorece la captación de un mayor número de personas; sea de forma conceptual o figurativa el diseñador pretende enviar mensajes significativos que inviten al diálogo entre el diseño y la tipografía con el usuario. El resultado que se espera son reflexiones de análisis que signifiquen experiencias satisfactorias.

\section{Referencias Bibliográficas}

Acaso, M. (2006) El lenguaje visual. España: Paidós.

Dascal, M. (1999) Filosofía del lenguaje II. Pragmática. Madrid: Trotta.

Diccionario Akal de Filosofia. (2004) España: ediciones Akal.

Fontana, R. (2012) Ganarse la letra. México: Universidad Autónoma metropolitana.

Lizarazo Arias, D. (2009) Iconos, figuraciones, sueños. Hermenéutica de las imágenes. México: Siglo XXI.

Martínez Leal, L. (1990) Treinta siglos de tipos y letras. México: Tilde

Real Academia Española. (1970) Diccionario de la Lengua Española. España: Espasa-Calpe.

Rodríguez González, A. (2005) Logo ¿Qué?. México: Siglo XXI Editores.

Ruder, E. (1983) Manual de diseño tipográfico. Barcelona: Gustavo Gili

Prieto Castillo, D. (2005) Diseño y comunicación. México: Ediciones Coyoacán.

Soriano, P. (2004) La mediación figurativa como historia del habitar. Argentina: No-buko.

Vilchis Esquivel, L. del C. (2006) Relaciones dialógicas en el diseño gráfico. México: Publicaciones ENAP.

Vilchis Esquivel, L. del C. (2004) Semiosis Hermenéutica de lenguajes gráficos no lineales. México: Imagen siete.

Vilchis Esquivel, L. del C. (2014) Metodología del diseño. México: Designio. 


\begin{abstract}
The study of design in its multiple manifestations is posed -in particular casesthrough antinomies; a confrontation of opposing concepts that expose their meaning in contrasting association. From the binomial: the conceptual and the figuration, dialogic reflections are established with the conceptual configuration of the linguistic sign and the figurative typographic representation, an antinomy proposed as a didactic strategy for the compression of two concepts frequently used in graphic design and that now It is exposed with the own resources of the typography. The conceptual configuration is illustrated with ten words with which there is a dialogue through the typographic signs to show their meaning or some of their meanings, without incorporating figurative elements that support the meaning. On the other hand, the figurative typographic representation postulates expressions with the morphological means of the typographic fonts available in the design editing programs; a level of dialogue with the design where the subject interprets the figuration in a more digestible way. This last section illustrates the concept of figuration with project steps of a single job. So far -at least in Mexico- there is no known study that addresses conceptual construction and typographic figuration in epistemological correspondence with dialogic relations with design, so this article aims to be a valuable reference document for the community of graphic designers, visual communicators and the general public.
\end{abstract}

Keywords: conceptual - figuration - meaning - typography - design.

Resumo: O estudo do design em suas múltiplas manifestações se coloca -em casos particulares- por meio de antinomias; um confronto de conceitos opostos que expõem seu significado em associações contrastantes. A partir do binômio: o conceitual e a figuração, estabelecem-se reflexões dialógicas com a configuração conceitual do signo lingüístico e a representação tipográfica figurativa, uma antinomia proposta como estratégia didática para a compressão de dois conceitos frequentemente utilizados em design gráfico e que agora é exposta com os recursos próprios da tipografia. A configuração conceitual é ilustrada com dez palavras com as quais se dialoga por meio dos signos tipográficos para mostrar seu significado ou alguns de seus significados, sem incorporar elementos figurativos que sustentem o significado. Por outro lado, a representação tipográfica figurativa postula expressões com os meios morfológicos das fontes tipográficas disponíveis nos programas de edição de design; um nível de diálogo com o design onde o sujeito interpreta a figuração de uma forma mais digerível. Esta última seção ilustra o conceito de figuração com etapas do projeto de um único trabalho. Até o momento - pelo menos no México - não há nenhum estudo conhecido que aborde a construção conceitual e a figuração tipográfica em correspondência epistemológica com as relações dialógicas com o design, então este artigo pretende ser um valioso documento de referência para a comunidade de designers gráficos, comunicadores visuais e os público geral.

Palavras chave: conceitual - figuração - significado - tipografia - design.

[Las traducciones de los abstracts fueron supervisadas por el autor de cada artículo] 